\title{
Searching for Success in a Successful IS Acquisition
}

\author{
Maija Ylinen \\ Dept. of Industrial and Information Management \\ Tampere University of Technology, Finland \\ maija.ylinen@tut.fi
}

\begin{abstract}
In today's business world, information systems (IS) are often acquired from an external vendor rather than being developed in-house. Although the number of studies related to the success of IS acquisitions has increased, there is limited understanding of the relationship between acquisition project success, the final IS success, and their role in defining whether the acquisition endeavor was ultimately successful. For instance, in public sector organizations, there is a tendency for the acquisition project to be conducted outside the acquiring unit. This means that success can be evaluated at multiple levels in the organization, and the different levels might not have identical aspirations related to the acquisition. This can cause organizational issues, especially when the evaluation of success is left in the hands of only one of these parties. In this paper, we study the facets of IS acquisition success by presenting differing aspects that are used in defining IS acquisition success, pointing out a contradiction between the formally measured success and the perceived success. As a result, we propose an IS acquisition success model. The study is conducted as a single case study of a public sector organization in Finland.
\end{abstract}

\section{Introduction}

Many studies have examined what makes information system (IS) acquisition a success or a failure [5, 10, 37]. Although several characteristics explaining the success or failure of IS have been identified (c.f. [3, 13, $14,16,37])$, they do not include the IS acquisition process or the IS implementation. These factors, however, are often seen as affecting the perceptions of success among different stakeholder groups, who have varied requirements and expectations regarding IS [4, 11, 19, $30,44]$. The stakeholders also take different roles during the acquisition project [11], making the situation even more complex. Taking these points together with the fact that the requirements of all the various stakeholders are rarely considered [4], and that failing IS implementations are regularly reported by the press

\author{
Samuli Pekkola \\ Dept. of Industrial and Information Management \\ Tampere University of Technology, Finland \\ samuli.pekkola@tut.fi
}

[36], IS acquisition and its success has become a scientifically interesting and timely topic.

Success is a multifaceted concept in the context of IS acquisitions since different measures, definitions, and characteristics of success co-exist [20]. In particular, the evaluation of success retrospectively, i.e., the post-acquisition evaluation, allows the organization to learn from successes as well as possible failures [5, 10]. However, the evaluation can be misleading, as it may reflect only the perceptions of the people responsible for the evaluation $[16,21,41]$. They thus ignore different stakeholders and their roles in defining success. This can result in dissatisfaction, cause problems inside the organization, and decrease the understanding of the acquisition and its effects on the organization.

In this paper, our aim is to understand different definitions of IS acquisition success. We aim to increase the understanding of these different views and their relations to one another. In addition, the role of different aspects in determining the official standpoint of success and the contradictions related to the definition of success are considered. Our research question is: How is IS acquisition success determined in a public sector organization, what are the roles of different stakeholders, and what is the value of IS for the organization? To answer this question, we conducted a qualitative case study in a public sector organization in Finland.

The paper is organized as follows: First, related research and background is provided. This is followed by research methods and the case description. Next, our findings are portrayed and then discussed. The paper ends with a concluding chapter.

\section{Theoretical background}

\subsection{IS acquisition}

We define an information system (IS) as an entity containing people, processes, data, models, technologies, and formalized language that forms a structure to support organizational functions [22, p. 11]. IS acquisition is defined as the process that includes formulating 
an idea for a new IS, from the initiation, design, development, and implementation, to the actual usage of the system [40]. This paper focuses mainly on the postimplementation, where the IS success is defined and evaluated. We perceive that post-implementation success may be dependent on the acquisition project and its success, as, for example, user involvement in the requirements specification and the systems development has an impact on the perceptions of success [c.f. 25].

The intention to acquire a new IS is often to reduce costs and improve the efficiency and effectiveness of different operations [31]. Sometimes acquisitions are also conducted in the attempt to enable process changes in the organization. This often necessitates new technological capabilities for achieving strategic objectives [20]. In order to attain acceptance of the acquisitions, these objectives are expected to be reached during or after the acquisition.

Public sector IS acquisitions usually follow a strict process, as regulation is often rigorous [28]. Moe [29] identified this process to follow subsequent phases: realization of the need for new IS, specifying the requirements, tendering, selecting, contracting, implementing, and completing the acquisition [30]. In practice, quite often the emphasis is on requirements specification and vendor selection to reduce the risk of complaints from other providers [29]. This makes public sector IS acquisitions complex and burdensome.

In the public sector, the complexity increases even more because of the number of stakeholders [1]. The stakeholders are the groups and individuals of the organization who, in the context of IS acquisitions, are somehow involved in the value creation of the acquisition and can affect or are affected by the actions taken and decisions made within the acquisition project [15]. Right from the start, stakeholder identification may be difficult, not to mention their consideration during the acquisition project $[5,10,11]$. Yet typically, three stakeholder groups include developers, users, and managers [38]. In public sector acquisitions, policymakers, activists, government agencies, and professionals are also critical operators [11].

As the stakeholder groups can have different values and expectations [4], their perceptions about what makes an IS acquisition successful may vary. Consequently, when evaluating success, separate stakeholder groups should not be ignored as they can affect the generation and realization of benefits in the long run [13].

\subsection{IS acquisition success}

2.2.1. Success of an IS acquisition project. Many characteristics define whether an IS acquisition project is a success. For example, simply completing the project is one of the most often mentioned characteristics $[4,10]$. If the acquisition project results in a system that is implemented, the measures of success focus more on whether the project resources were used in the best possible way, i.e., whether the time, cost, and quality objectives were met [12]. However, not every acquisition project defined as successful fulfills the budget and schedule objectives [24]. This raises a question; is measuring the project resources sensible? As different kinds of intangible benefits, such as user or employee satisfaction and long-term financial benefits, are hard to define, measure, and assign to a certain IS, the cost and schedules become easy and evident measures [20].

Another means to analyze the project success is to examine whether the project fulfilled its objectives [2, 16]. Yet, as pointed out by Cooke-Davies [10], the expectations and whether they are met is often the only frame of reference of the success in actual IS projects. Since the objectives are hard to measure and formalize, they are not often measured after the acquisition [20].

In addition, the expectations are not evidently linked with the IS objectives. Different stakeholders and their expectations may differ from the formal objectives. This leads to partial consideration or even ignorance of different stakeholders' expectations, wishes, and goals [5, 10]. Moreover, if the expectations are too high, even a successful project can be perceived as a failure. On the other hand, users who do not expect substantial operational improvements to their work can already be satisfied with small incremental improvements [5].

All this underlines the need for managing the stakeholders and their expectations [5]. The importance of gaining user acceptance cannot be underestimated. This is emphasized in terms of resistance toward organizational change, which is evidently unavoidable with new IS [26]. How to deal with and overcome this resistance is tightly connected with the success of an IS acquisition project [16].

2.2.2. Success of IS. IS acquisition success can also be viewed from the viewpoint of the success of the new system $[6,13,14,38]$. Here, the evaluation of the benefits of the new system are significant $[13,14,41]$. Yet these benefits emerge only in conjunction with the acquisition process, the business development process, and the IS development process [20]. Consequently, in addition to evaluating IS functionalities, the system and its organizational integration must be considered [47].

All this emphasizes the alignment of business processes and their IS support. The evaluation of the IS success is thus encapsulated to the evaluation of the IT- 
business alignment [9]. This is emphasized since it is possible to develop business processes for new IS. This kind of process development may, however, occur through self-organizing, where operational environment and organizational strategy are ignored. In the worst case, this can cause the organization to lose its business focus and forfeit its competitive position [9]. While changes in the organization's operations are not easy to implement or accept [39], evaluating all the different kinds of process changes is critical for IS success. If organizations succeed in aligning IT and business, they often outperform others that do not give attention to the process $[9,39]$. Therefore, IS success is linked to whether the processes are constantly in line with the organization's strategic objectives [9].

Nonetheless, the successful implementation and integration of the IS does not necessarily mean that the IS itself will be a success. Consequently, the IS also needs to be evaluated. One of the most used frameworks for this is the DeLone \& McLean IS success model $[13,14]$. It considers three different quality aspects: system, information, and service quality, which in conjunction create the basis for user satisfaction; intention to use and eventually the use of the system; and benefit realization [14]. From the IS acquisition viewpoint, all DeLone and McLean quality factors are closely related to the user's expectations and desires toward the IS. System quality is a measure that defines how well the system supports the operations [34], while information quality defines whether information supports decision-making [23, 25, 34]. Service quality pinpoints the gap between provided and expected services [17]. Consequently, quality factor perceptions are strongly related to the users' and other stakeholders' expectations and objectives toward the new IS. These expectations, however, evolve over time, and can be influenced by the acquisition project, for instance.

Even user satisfaction is not a stable condition. The users need hints of future benefits to motivate them to use the system $[41,43]$. This is closely related to the usefulness of the IS $[6,8,41]$. The level of usefulness can vary in different parts of the organization, as the IS provides different benefits for different users, or the benefits can be targeted only to a certain user group [17]. Users who feel that they gain benefits from the IS are more prone to use it [37].

As a result, one of the most typical means to measure IS success is the use of the system, since the users are presumably expected to benefit from it $[12,13]$. The use of the system is also the key factor in generating benefits for the organization $[14,37]$. The use thus enables the realization of the acquisition objectives. However, it has been argued that the use is not a good success measure $[8,16]$. There might not be any alternatives, or the users might spend more time with a poor system unsuitable for the task without gaining any benefits $[41,44]$.

Nevertheless, presumed benefits are usually the main reason for acquiring a new IS [7]. Desired benefits are thus closely related to the acquisition goals, which should be bound with the strategy of the organization. Consequently, IS acquisition benefits are often related to achieving different objectives of the organization [38], which eventually define whether the acquisition was worth the effort and hence considered successful [42].

\section{Research method and the case}

\subsection{Research method}

This study follows an interpretive qualitative single case study approach [45]. We study an IS acquisition project that took place from 2012 to 2014 in a large municipality in Finland. The case was selected because the municipality advertised it as being an example of a successful acquisition. The data was collected via interviews with the main actors participating in different roles in the acquisition. The aim was to gain understanding about different opinions on whether they perceived the new system successful. Interview questions were open-ended, semi-structured, and theme-based [32]. They were conducted on the interviewees' premises and audio-recorded. A list of interviewees is presented in Table 1.

Table 1. The list of interviewees

\begin{tabular}{|l|l|}
\hline Interviewee & Type of interview \\
\hline Project manager & Individual interview, two interviewers \\
\hline Main user A & Individual interview, two interviewers \\
\hline Main user B & Individual interview, two interviewers \\
\hline Work organizer A & Group interview, two interviewers \\
\hline Work organizer B & Individual interview, one interviewer \\
\hline Care person A & Group interview, one interviewer \\
\hline Care person B & Group interview, two interviewers \\
\hline Care person C & Group interview, two interviewers \\
\hline
\end{tabular}

All the interviews were conducted and analyzed in Finnish. Only illustrative quotations were translated to English. Data analysis was data-driven [46], i.e., different themes related to the benefits and success were first identified. Then similar themes were grouped (see Table 2 for examples). The procedure continued until the grouping did not evolve. This resulted in a list of concepts, framing the IS acquisition success. 
Table 2. Examples of the coding

\begin{tabular}{|c|c|c|}
\hline Extracts from the data & Codes used & Interpretation \\
\hline $\begin{array}{l}\text { "There is no longer time for me to go to the field. Before [the } \\
\text { new system] I had the time for that." [Work organizer A]. }\end{array}$ & $\begin{array}{l}\text { "Changed work de- } \\
\text { scription", "Longing } \\
\text { for old days" }\end{array}$ & \multirow{3}{*}{$\begin{array}{l}\text { These extractions relate to the care } \\
\text { people attitude towards the changes } \\
\text { in their work. Care people do not } \\
\text { think that the business processes of } \\
\text { the home care unit are positive } \\
\text { ones. }\end{array}$} \\
\hline $\begin{array}{l}\text { "This customer-orientation is not the same as it was some two } \\
\text { or three years ago. Only the percentages matter." [Care person } \\
\text { C] }\end{array}$ & $\begin{array}{l}\text { "Changed work de- } \\
\text { scription", "Longing } \\
\text { for old days" }\end{array}$ & \\
\hline $\begin{array}{l}\text { "It is quite common that [the nurses] change the order [of the } \\
\text { clients]." [Main user A] }\end{array}$ & "Resistance to change" & \\
\hline $\begin{array}{l}\text { "That all you have to do is to push } \\
\text { a button and the work lists are ready" [Work organizer A] }\end{array}$ & $\begin{array}{l}\text { "Unrealized expecta- } \\
\text { tions" }\end{array}$ & \multirow{2}{*}{$\begin{array}{l}\text { These extracts indicate that the } \\
\text { expectations of work organizers } \\
\text { were not met. Hence their objec- } \\
\text { tives related to the project were not } \\
\text { realized, causing dissatisfaction. }\end{array}$} \\
\hline $\begin{array}{l}\text { "[The system optimized] routes as the crow flies. However, if } \\
\text { you give a half kilometer range to a cyclist, [the cyclist] might } \\
\text { not be able to go the way the crow flies." [Work organizer A]. }\end{array}$ & $\begin{array}{l}\text { "Poor IS functionali- } \\
\text { ty", "Unrealized ex- } \\
\text { pectations" }\end{array}$ & \\
\hline $\begin{array}{l}\text { "[The vendor] was clearly learning how to do the job" [Project } \\
\text { manager] }\end{array}$ & $\begin{array}{l}\text { "Lacking vendor com- } \\
\text { petence" }\end{array}$ & \multirow{3}{*}{$\begin{array}{l}\text { These extracts indicate that there } \\
\text { were severe issues with the vendor, } \\
\text { causing issues to the acquisition } \\
\text { project execution. }\end{array}$} \\
\hline $\begin{array}{l}\text { "Mostly they did not even ask how things were going or how } \\
\text { satisfied we were with things." [Main user B] }\end{array}$ & $\begin{array}{l}\text { "Issues with vendor } \\
\text { cooperation" }\end{array}$ & \\
\hline $\begin{array}{l}\text { "This unexpected redevelopment of the optimization function- } \\
\text { ality caused that the project was stretched by almost a year." } \\
\text { [Project manager] }\end{array}$ & "Development issues" & \\
\hline
\end{tabular}

\subsection{The case}

The case is about acquiring a new IS for an elderly home care unit of a municipality. The unit is part of the social services sector, and serves over 2000 clients a year. The clients1 live at their homes, but for one reason or another, they need assistance, for example, in cooking, cleaning, going outside, or getting medication. The clients' needs and their number have increased rapidly recently, and organizing the home care has become more challenging. This increasing need and the desire to improve the processes resulted in an idea for an ICT-based solution. The idea originated from the home care unit. The city committee provided its political support and approval. This eventually resulted in the home care unit obtaining software for organizing the work (a route optimization system) and a mobile application to support the nurses and their reporting when visiting the clients.

With the route optimization software, the routes and visit times of clients are optimized by a computer. This process was previously completed by a nurse with

\footnotetext{
${ }^{1}$ A client refers to elderly people, people with disabilities, or people in general need of home care. The nurses visit clients regularly (daily, every second day, or weekly) to perform different services in order to allow the clients to live in their own homes rather than in nursing homes.
}

pen and paper. The optimization is prepared using multiple variables, including the location of the client, the client's care needs, the nurse's ability to perform the tasks the client requires, and the time window when the care is needed.

The mobile application is a tool for nurses to access the client information, report what actions they have performed during their visit, and make notes about the client's health. All the work that the nurses used to do at the end of their workday on the office computer is performed on the mobile application. The application also provides information about the nurses' daily visits and the routes they are to take from one client to another.

After two years of using the systems, the municipality and their CIO consider the acquisition an exemplary case of successful IS acquisition. 


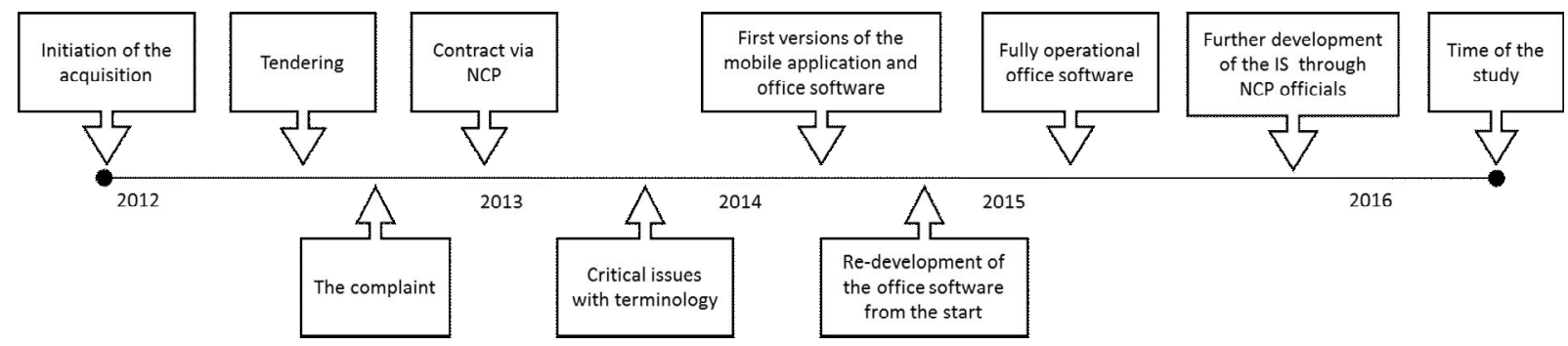

Figure 1. The significant phases of the acquisition

3.2.1. The acquisition project. The acquisition project lasted from the beginning of the year 2012 until the end of year 2014. However, even after this timeframe, the home care unit carried out some significant development efforts. Figure 1 illustrates the main phases of the project.

Despite rigorous preparation and a clear vision of what the municipality wanted, the acquisition project did not go as smoothly as initially expected. Even before any contracts were signed, one of the vendors who was participating in the IS tendering issued a complaint and eventually won. As a result, the municipality could not continue the acquisition with the selected vendor, the one they preferred. Since the municipality also owned shares in a National centralized purchasing organization (NCP), they decided to acquire the system through the "back door," the NCP, which had a contract with the system provider they preferred. They consequently obtained the system they desired but only via a third-party operator and without a direct contract with the system provider, since the NCP required all communication to go through them. However, they did not have enough resources to keep the communication fluent, so communication between the acquisition team and the vendor was minimal.

In addition, the contract was not interpreted coherently by the various parties. As the vendor did not have previous knowledge of health care services, many misunderstandings emerged that were difficult to solve. "In sum, we have wasted hundreds of hours just because the terminology was not mutually clear to all" [Main user B]. As a result of the misunderstandings, the first version of the optimization software was unusable by the home care unit. The vendor was forced to start the development afresh. "This unexpected redevelopment of the optimization functionality caused the project to stretch by almost a year" [Project manager].

3.2.2. The acceptance. Despite the difficulties, the acquisition project ended as planned. Ultimately, both systems were implemented and taken into use. Although the nurses were not familiar with the smartphone-based mobile reporting, they perceived it positively from the very beginning, even though "the first version was simply bad. Nevertheless, the nurses were happy" [Main user B]. This was mainly because "[the mobile reporting] made the work much easier, as now you can look at the client's information from the phone when something comes to mind" [Care person A]. This decreased the nurses' mental stress since they could gain access to client information from the client's home.

The route optimization and nurse coordination system "has many good and bad sides" [Work organizer B]. Since the system was taken into use before it was finished and working as expected, the users never learned to trust that it could help them with their tasks. In particular, the route optimization, one of its main functionalities, was not supported in the beginning. This caused the system to be generally disliked by both the nurses and the work organizers. Even though the system improved significantly during the implementation, its use did not respond to the vision "that all you need to do is to push a button and the work lists are there, ready to be used" [Work organizer A], which was the original sales speech and the users' expectation. In addition, the optimization system generated routes that conflicted with the users' tacit knowledge, and hence, "I tend to modify them way more than is necessary" [Work organizer B].

The lack of trust toward the route optimization resulted in the work organizers doing their work both on paper and in the new IS. Partly due to this, "there is no longer time for me to go to the field. Earlier I had the time for that" [Work organizer A]. Thus, the original intention to decrease the time spent on route optimization work did not materialize, even after the learning period. In addition, when the work organizers did not modify the proposed routes, the nurses objected by not following the routes. One of the users pointed out that "It is quite common that [the nurses] change the order [of the clients]" [Main user A]. Both the nurses and the clients were reluctant to change their previous routines. The nurses previously visited their clients at the most suitable time for them. As the nurses desired to serve their clients in the best possible way, they often did not follow the times generated by the software, because 
arriving at the clients' homes in some other time was uncomfortable for all.

The route optimization system also gave strict transition times for travelling between the clients. As a result, the nurses left their clients earlier in order to have enough transition time. "Because it takes so much time to travel the distances, the nurses felt they needed to leave the clients earlier than planned [..] However, it sometimes seems that the visits are shortened, not because the nurses are in a rush but because they think that they are" [Work organizer B]. This led to decreased service time at the clients' premises and possibly not giving the clients the amount of care they needed, ordered, and paid for.

Although the nurses had low expectations toward mobile applications, the improvements "eased the work a lot and saved a lot of time" [Care person A]. The feedback was positive. On the other hand, the route optimization system did not meet the expectations of either the nurses or the work organizers. The nurses were especially disappointed with the viewpoint of optimizing the nurse's workday in order to maximize the number of clients per day rather than focusing on the time spent with the client. This obviously resulted in the system being not well accepted.

3.2.3. The success. When the acquisition was planned, one of the main objectives was to increase the time spent in actual home care beyond $60 \%$ of the nurses' working day. By the summer of 2016, efficiency had risen from $56 \%$ to $59 \%$. The acquisition, at least in the management level, was thus regarded as an evident success. This statement was made despite what the acquisition project's project manager concluded: "This is such an entity that everything affects everything. It is getting quite hard to say, certainly, that this is because of [the new IS] and that the savings we have gained are linked to the usage of the new IS" [Project manager].

The success was, in fact, contradictory. Top management considered the acquisition an exemplary case of a successful IS acquisition. "Of course, this is a successful acquisition; we got something" [Main user B]. At the same time, the nurses consider that "the old way was way better, seriously" [Care person C] since they felt they have been forced to follow new and worse processes that do not take into consideration their needs or the needs of their clients. One of the nurses argued that "this customer-orientation is not the same as it was some two or three years ago. Only the percentages matter" [Care person C]. Consequently, although the goals have been reached, the question arises whether the measures of success tell the whole truth. One of the members of the project team encapsulated it thus: "One can only see [the success] in a few years' time. No one can evaluate it fully right now, especially as the system is not yet in the shape it should be" [Main user B].

\section{Findings}

There was a clear view that because the project team managed to get the project completed despite the challenges, the acquisition project was a success. This view is held even though the system is still not as intended: "Of course this is a successful acquisition; we got something" [Main user B]. This perception was particularly common among the acquisition project members, most of whom do not use the system in their daily work. They also considered the project successful even though it exceeded the budget and the schedule and even though there "are still some issues that are under settlement by the lawyers" [Main user B].

Given this view, the success of the IS acquisition was assessed by how well the acquisition reached its objectives, not how well the acquisition project was conducted. The main objective was to enable a process change by introducing a new system to the home care unit. As the nurses were using new reporting application and the work organizers used the route optimization software, the management's objectives were obtained. The acquisition was defined as a success. "I think this [acquisition] is a success, just from the point of view that the work our home care does has made a jump in a more modern direction and has met the current needs" [Project manager].

These process changes in the home care unit were two-fold. First, the route optimization software was intended to help the work organizers with their task of arranging the daily visits to the clients more efficiently. Second, the nurses were able to report their visits and care activities directly to the database instead of first writing the notes in a notebook and then rewriting them to a computer. The reporting systems thus removed the double recordings and consequently freed the nurses' time for home care work. This, however, did not give the nurses more time with their current clients; rather, it gave them more clients.

The nurses did not endorse this. "Nothing is good enough anymore [..] You can have this kind of disaster day every once in a while, as long as every day is not like that [..] It is a fact that you cannot take care of people when you are tired, since you start to make mistakes, and when there have been several of these horrible days, it is terrible to go home and know that you have done your work poorly" [Care person $\mathrm{C}$ ].

This notion questions the managers' perception of success; can increased hours with clients alone indicate a success? The nurses are able to report and record information during the visits, so they do spend more 
time in care work, in principle. However, although it may increase the time with the clients, it does not correspond to the time in care work in practice, as either reporting or extra clients eats the time savings. The changes in the home care unit and new systems solved the issue of growing need from the managerial point of view. Yet, it did not consider the users and possible later consequences. This problem became emphasized when the nurses requested changes in the order of the visits, and the work organizers modified the work lists often. These actions deteriorated the realization of the original objectives of the managerial level.

Consequently, individual perceptions about the acquisition success are strongly related to the benefits the individuals have gained in relation to the original objectives to help nurses cope with an increasing workload. On the one hand, the users were satisfied with the mobile reporting application, as it helped them with their tasks, but not with the route optimization software, which did not permit the nurses to do their jobs as well as they would have liked. On the other hand, the organization's objective, with which the acquisition was initially approved, was to carry out a process change to increase efficiency. This was considered to have been successfully achieved.

Hence, the perception of the acquisition success is not straightforward; based on the home care unit's original needs, an efficiency measure was created to get the acquisition accepted. This measure was then used by the organization responsible for the acquisition to define its success. How well the measure correlated with the original needs and the effectiveness of the IS were not considered. Consequently, the organization and their top management consider the acquisition to be a success, whereas the users consider the situation to be more complex. This interpretation strengthened over time when the project was completed and the business processes re-engineered. The new process and its IT support were not ideal, as they exhausted the nurses.

\section{Discussion}

Previous literature on IS acquisition sees success from one of the following perspectives: IT adoption, IS success, or project success. These are, however, rarely discussed together [35]. In this paper, we have linked these views together to form a generic depiction of the factors of IS acquisition success. The model itself does not challenge earlier findings per se, but attempts to illustrate their relationships. This is presented in Figure 2. Our study underlines four factors contributing to the success of an IS acquisition. These are: acquisition project and its execution, business process reengineering and its success, the realization of the ac- quisition objectives from the users' point of view, and the realization of the acquisition objectives from the organization's point of view.

Completing the project, i.e., the fact that the project is finalized at all, is a substantial measure of success. Obviously, completing the project, no matter how well or how poorly, enables the attainment of other goals. This parallels with the literature in which project execution is considered a significant enabler of success $[4$, 10]. The system implementation also enables business process re-engineering [21], as work routine changes and development become possible, increasing organizational efficiency. This notion corresponds with the business IT alignment perspective [19], which emphasizes organizational change, appropriateness of the IS, and project execution for making the acquisition successful.

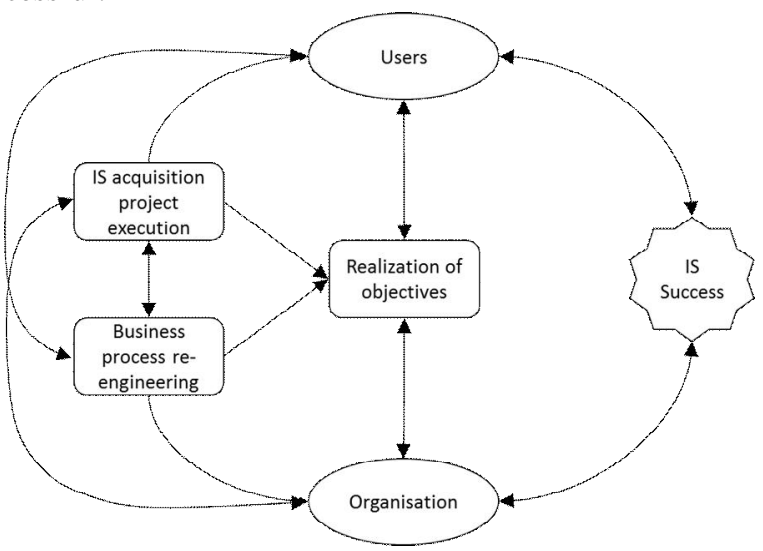

Figure 2. Success measures of IS acquisition

Although our model resembles others in the project management literature, there is a significant difference. Project management literature emphasizes the factors of time and cost as significant measures of success [4, 12, 24]. However, in our case, these factors did not influence the perception of success at all.

Figure 2 shows that project execution and organizational business process re-engineering both influence the realization of the acquisition objectives. Yet the views may differ, depending on the users' or organization's point of view. For instance, in our case, although the organization has set formal objectives, they were not mutually shared and acknowledged inside the organization by its employees. In addition to formal objectives, the users had their own expectations toward new work processes and IS. The employees then formed their own perceptions of the realization of the objectives in the same manner as the management comprised the formal view. This was identified earlier as all stakeholders cannot be satisfied similarly [18, 27].

Obtaining the objectives is often used as a basis for defining success. However, we divide IS acquisition 
objectives into two factors: organizational objectives and users' objectives. The role of objectives in the definition of success also emphasizes the selected scope of IS acquisition success instead of IS success or project success. As the users' and organization's objectives were defined before the decision to start the procurement, the whole acquisition can be considered to have a role in defining the success.

Although all stakeholders were not considered equally, neither the IS acquisition nor the process changes would have been possible without their involvement. The management, included in the Organization component in Figure 2, made the IS acquisition and process changes possible by leading the organization through the changes. However, the changes, enabled and to some extent forced by the IS, also affect the objectives the management has set for the project. This is also the case with the users, who are the most affected by the acquisition. They have a new system to use and new processes to follow, but they can also choose not to use the system or follow the processes, depending on their perceptions of the success of the acquisition.

The objectives and whether they were met affect the users' perceptions of the success of the acquisition. Similarly, the organization has formed its own perception [16]. The success of IS acquisition is consequently dependent upon the success of the acquisition project, the success of the business process re-engineering, and the realization of the objectives that are formed before, during, and after the acquisition project [33]. These are all recognized as factors of IS acquisition success. However, defining success is ambiguous, since all stakeholders may not necessarily share the formal objectives [6, 8]. Various stakeholders most likely have their own expectations.

All in all, we found IS acquisition success to be two-dimensional. There is the success defined by the organization and the success defined by the individuals, both of which are dependent on whether the acquisition meets the expectations and provides the expected benefits. However, these benefits are highly dependent on different stakeholders and their actions, as well as the development and success of the implementation of new IS and business processes. It seems that success of the acquisition project has a small role in the definition of IS acquisition success as a whole. In the long run, success is dependent on the success of organizational change. For the organizational change to be focused on improving operations with the new IS, it is necessary that all of the factors of IS acquisition success be considered when the IS acquisition success is evaluated. In our case, the role of the users was ignored. This caused imbalance and issues in the operations, and was harmful for the organization's operations. Sometimes these problems can be fixed if they are correctly identified. The evaluation of success should thus not focus on a few predefined measures, but rather should consider the complexity of the topic.

\section{Conclusion}

In this study, IS acquisition success was studied in the context of a public sector organization. As the case clearly indicates, the success of an IS acquisition contains two separate levels: the success defined by the organization and the success experienced by the users and other stakeholders. Executing the acquisition project and re-engineering the business process enabled by new IS allowed the organization to achieve its objectives. This justified the acquisition from the management's point of view; thus, they considered it a success. However, neither the project execution nor the process re-engineering were fully beneficial to the users of the new IS. Consequently, the users did not consider the acquisition a success, even though they were satisfied with those changes they perceived to be beneficial.

This result demonstrates that IS acquisition success is a complex and ambiguous concept. This seemingly simple and self-evident statement becomes more compelling given the fact that our organization is ignoring it. Even now, several years after the acquisition project was completed, the management has managed to ignore the users' dissatisfaction, which has escalated into problematic behavior.

Management's indifference is hindering the realization of the acquisition benefits, as the nurses do extra work to avoid following the new processes defined by the management and the new way of working. Hence, we emphasize the importance of understanding the organizational structure of IS acquisition success and the importance of taking it into consideration. We also identify different characteristics of IS acquisition affecting the perception of its success and their relationships to each other. These provide new knowledge for researchers.

Practitioners benefit from this model and its implications, as they can better understand the complexity of an IS acquisition. An IS acquisition is not only about acquiring or implementing IS, but also about considering several stakeholders and different process changes over time.

Our main limitation is that the findings are based only on a single case. Consequently, transferring or generalizing them must be done cautiously. Additionally, the public sector context should be considered, as some of the challenges could be typical only to public sector organizations. Moreover, we interviewed only the people who were participating in the acquisition 
project. They might have described the situation more positively because they did not want it to be perceived as a failure. Finally, Scandinavian workplace democracy may have had some implications to the nurses' reactions and reluctance.

Deeper analysis is needed regarding different variables and characteristics and how they evolve over time, as well as examining other contexts. It would also be beneficial to study how increased understanding of the complexity of the acquisition affects the organization and its operations and eventually generates benefits.

\section{Acknowledgements}

This study was funded by the Academy of Finland grant \#306000.

\section{References}

[1] A. Alanne, P. Hellsten, S. Pekkola, I. Saarenpää, "Three positives make one negative: public sector IS procurement", In: International Conference on Electronic Government, Springer International Publishing, 2015, pp. 321-333.

[2] R. Atkinson, "Project management: cost, time and quality, two best guesses and a phenomenon, its time to accept other success criteria", International Journal of Project Management, 17(6), 1999, pp. 337-342.

[3] K. Axelsson, U. Melin and F. Södeström, "Analyzing best practice and critical success factors in health information system case -Are there any shortcuts to successful IT implementation" In: ECIS 2011 Proceedings. AISeL, 2011, pp. 2157-2168.

[4] D. Baccarini, "The Logical Framework Method for Defining Project Success", Project Management Journal, 30(4), 1999, pp. 25-32.

[5] D. Baccarini, G. Salm and P.E. Love, "Management of risk in information technology projects", Industrial Management \& Data Systems, 104(4), 2004, pp. 286-295.

[6] E.R. Bravo, M. Santana and J. Rodon. "Information systems and performance: the role of technology, task and the individual", In: Behavior \& Information Technology, 34(4), 2015, pp. 247-260.

[7] J. Campbell, C. McDonald and T. Sethibe, "Public and private sector IT governance: Identifying contextual differences". In: Australasian Journal of Information Systems, 16(2), 2009, pp. 5-18.

[8] M. Carter, S. Petter and A.B. Randolph, "Desperately Seeking Information in Information System Research", In: Thirty Sixth International Conference on Information Systems, Fort Worth, 2015, pp. 1-9.
[9] Y.E. Chan and B. H. Reich, "IT alignment: what have we learned?", Journal of Information Technology, 22, 2009, pp. 297-315.

[10] T. Cooke-Davies, "The "real" success factors of projects", International Journal of Project Management, 20 2001, pp. 185-190.

[11] W. Currie and E.A. Whitley, "Entangled Stakeholder Roles and Perceptions in Health Information Systems: A Longitudinal Study of the U.K. NHS N3 Network", Journal of the Association for Information Systems, 17(2), 2016, pp. $107-61$.

[12] K. Davis, "A method to measure success dimensions relating to individual stakeholder groups", International Journal of Project Management, 34, 2016, pp. 480-493.

[13] W.H. DeLone and E.R. McLean, "Information Systems Success: The Quest for the Dependent Variable", Information Systems Research, 3(1), 1992, pp. 60-95.

[14] W.H. DeLone and E.R. McLean, "The DeLone and McLean Model of Information System Success: A Ten- Year Update", Journal of Management Information Systems, 19(4), 2003, pp. 9-30.

[15] Freeman, R.E., J.S. Harrison, A.C. Wicks, B. Parmar and S. de Colle, "Stakeholder Theory The State of the Art", Cambridge University Press, 2010, 343 p.

[16] S. Goldfinch, "Pessimism, Computer Failure, and Information Systems Development in the Public Sector", In: Public Administration Review, 67(5), 2007, pp. 917-929.

[17] N, Gorla and T. M. Somers, "The impact of IT outsourcing on information systems success". Information \& Management, 51, 2014, pp. 320-335.

[18] T. Gross and S. Pekkola, "Three levels of failure: Analysing a workflow management system.” In: H. Isomäki \& S. Pekkola (eds.) Reframing Humans in Information Systems Development. Springer London, 2010, pp. 191-210.

[19] P. Hallikainen, J. Heikkiä, K. Peffers, T. Saarinen and F. Wijnhoven, "Evaluating Information Technology Projects in Finland: Procedures, Follow-Through, Decision-Making and Perceived Evaluation Quality", Journal of Global Information Management, 6(4), 1998, pp. 23-33.

[20] P. Hallikainen and L. Chen, "A Holistic Framework on Information Systems Evaluation with a Case Analysis", The Electronic Journal Information Systems Evaluation, 9(2), 2005, pp. 57-64.

[21] M. Hammer and J. Champy, (2009). Reengineering the Corporation: Manifesto for Business Revolution, HarperCollins Publishers Inc., New York, 2009, 258 p.

[22] R. Hirschheim, H.K. Klein and K. Lyytinen. "Information Systems Development and Data Modeling Conseptual 
and Philosophical Foundations", Cambridge University Press, 1995, 289 p.

[23] Y.W. Lee, D.M. Strong, B.K. Kahn and R. Y. Wang "AIMQ: a methodology for information quality assessment", Information \& Management, 40, 2002, pp. 133-146.

[24] L. Lee-Kelley and K.L. Loong, “Turner's FiveFunctions of Project-Based Management and Situational Leadership in IT Services Projects", International Journal of Project Management, 21(8), 2003, pp. 583-591.

[25] T. Lynch, and S. Gregor, "User participation in decision support systems development: influencing system outcomes", European Journal of Information Systems, 13(1), 2004, pp. 286-301.

[26] M.M. Lynne, "Technochange management: using IT to drive organizational change", Journal of Information Technology, 19(1), 2004, pp. 4-20.

[27] L. McLeod and S.G. MacDonell, "Factors that Affect Software Systems Development Project Outcomes: A Survey of Research", ACM Computing Surveys, 43(4),

2011, pp. 24-56.

[28] C.E. Moe, A.C. Risvand and M.K. Sein, (2006). "Limits of public procurement: information systems acquisitions". In: International Conference on Electronic Government, Springer, Berlin Heidelberg, 2006, pp. 281-292.

[29] C.E. Moe, "Research on Public Procurement of Information Systems: The Need for a Process Approach", Communications of the Association for Information Systems, 34(1), 2014, pp. 1391-1335.

[30] C.E. Moe and M. Newman, "The Public Procurement of IS - A process View", In: 47th Hawaii International Conference on System Science, IEEE, 2014, pp. 2158-2167.

[31] S. Mulyani, R. Hassan and F. Anugrah, "The Critical Success Factors for the Use of Information Systems and its Impact on the Organizational Performance", International Business Management, 10, 2016, pp. 552-560.

[32] M.D. Myers and M. Newman, "The qualitative interview in IS research: Examining the craft", Information and Organization, 17, 2007, pp. 2-26.

[33] F.F.H. Nah and S. Delgado, "Critical Success Factors for Enterprise Resource

Planning Implementation and Upgrade", Journal of Computer Information Systems, 2006, pp. 99-113.

[34] R.R. Nelson, P.A. Todd and B. H. Wixom, "Antecedents of Information and System Quality: An Empirical Examination Within the Context of Data Warehousing", Journal of Management Information Systems, 21(4), 2005, pp. 199-235.

[35] T.D. Nguyen, T.M. Nguyen and T.H. Cao, "The Relationship between IT Adoption, IS Success and Project Suc- cess", In: 2016 International Conference on Advances in Computing, Communications and Informatics, 2016, pp. 2124.

[36] Pekkola, S, E. Niemi, M. Rossi, M. Ruskamo and T. Salmimaa, "ERP Research At ECIS And ICIS: A Fashion Wave Calming Down?", In: Proceedings of the 21st European Conference on Information Systems, 2013, pp. 1-12.

[37] S. Petter, W. DeLone and E. McLean, "Measuring information systems success: models, dimensions, measures, and interrelationships", European Journal of Information Systems, 17, 2008, pp. 236-263.

[38] S. Petter, W. DeLone and E. McLean "The Past, Present, and Future of "IS Success"”, In: Journal of the Association for Information Systems, 13, 2012, pp. 341-362.

[39] J. Ram, D. Corkindale and M.-L. Wu, "Implementation critical success factors (CFSs) for ERP: Do they contribute to implementation success and post-implementation performance?,", International Journal of Production Economics, 2(1), 2013, pp. 157-174

[40] J.J. Schiele and C.P. Clifford, "Professional service acquisition in public sector procurement A conceptual model of meaningful involvement" International Journal of Operation and Production Management, 26(3), 2006, pp. 300-325.

[41] P.B. Seddon, "A Re specification and Extension of the DeLone and McLean Model of IS Success", Information System Research, 8(3), 1997, pp. 240-253.

[42] D. Sedera and G. Gable, "A Factor and Structural Equation Analysis of the Enterprise System Success Measurement Model".. In: Twenty-Fifth International Conference on Information Systems, 2004, pp. 449-464.

[43] M.M.N Sharabati, A. Sulaiman and N.A.M. Salleh, "End User Satisfaction and Individual Performance Assessments in e-Procurement Systems", International Journal of Computer Theory and Engineering, 7(6), 2015, pp. 503-509.

[44] T.M. Somers and K. Nelson, "The Impact of Critical Success Factors across the Stages of Enterprise Resource Planning Implementations", In: 34th Hawaii International Conference on System Sciences, IEEE, 2001, pp. 1-10.

[45] G. Walsham, "Interpretive case studies in IS research: nature and method", European Journal of Information Systems, 4, 1995, pp. 74-81.

[46] G. Walsham, "Doing interpretive research" In: European Journal of Information Systems, 15, 2006, pp. 320-330.

[47] J.P. Xin Dai and F. Zhiyuan, "Senior Executive and Staff: What Effect do They Exert on Success of Information System?", In: 10th International Conference on e-Business Engineering, IEEE, 2013, pp. 441-444. 